\title{
The Construction of Identity and Identification in Tim Minchin's Storm
}

\author{
Lennart Brieger
}

\section{Introduction}

\subsection{Storm and Identities}

Tim Minchin's beat poem Storm is an account of the clash of two people's world views. The narrator of the text and his wife ${ }^{1}$ visit friends for dinner, and a fifth person called 'Storm' is also invited. It soon turns out that the narrator's and Storm's opinions on the nature of knowledge, truth, spirituality and other issues seem to differ fundamentally, and thus, an argument that constitutes most of the content of the poem ensues.

The conflict between the two stubbornly defended, mutually exclusive world views in Storm seems to show that the two opponents are not simply in disagreement over the issues they discuss. Rather, their persistence appears to indicate that the topics argued over are of far more importance to them than other topics might be. Their opinions on the issues, thus, seem to matter to them as if they were not only part of their views of the world, but part of their self-conceptions - their identities, one might say. Thus, it could be argued that the displayed argument is not just one of contesting ideas, but of seemingly irreconcilable identities. 1 The narrator will be referred to as male, as he explicitly mentions his "cock" (Minchin 177),
meaning his penis. 
However, a third identity is involved in the quarrel. While perceiving Storm, the recipient of the text is inevitably confronted with both the views of the narrator and those of Storm. The way in which he or she evaluates their claims probably does not merely depend on his or her identity, but also on the way both the characters and their arguments are presented in the text. Since the account of the happenings at the dinner party is entirely delivered from the perspective of the narrator, it is rather subjective and seemingly aims to convince the recipient of the correctness of the narrator's views.

The purpose of this paper is to examine how certain elements of the text can influence the reader's identity, by causing him or her to agree with the narrator ${ }^{2}$. Specifically, the role of the narrative structure and the capacity of poetic qualities of Storm, mostly imagery, to influence identification by giving the reader pleasure will be examined. The narrative structure is of interest because of the inevitable subjectivity of the narration that arises from the narrator's rendering of it. The narrator's point of view may certainly serve to show things, happenings and people from a certain perspective (Petersen 2), thereby showing them in a certain light to the recipient of the text, which may influence his or her views and identity in a certain way. Furthermore, "Poetry is something for everyone to enjoy" (Nelson 1), and poetic aspects of the text thus can presumably make the reader more readily accept and assume opinions that are expressed in a way that gives him or her pleasure. As Paul Bloom states, "we tend to like those who give us joy." (137-138), and perhaps we can even identify with them.

\subsection{The Transcription}

An obstacle that had to be cleared in order to conduct a literary analysis of the effects of Storm on the reader's identity is that the poem has, as yet, not been published in written form, but only as performed by Minchin himself on CD and DVD. It has, however, also been released on the internet as part of a video entitled Tim Minchin's Storm the Animated Movie, where Minchin recites the poem and the plot is simultaneously shown as an animated film, accompanied by music. It is this version of Storm that has been transcribed for the purpose of this paper and that will be examined here. A complete analysis of the text, performance and possibly even the music in the background of the performance, would exceed the aims of this paper by far. Therefore, the analysis will focus on what is said in the transcribed text, not on how Minchin recites the poem ${ }^{3}$.

2 A different approach would be to examine the narrator's rendering of the events for instances of self-subversion, which might indeed prove fruitful, yet will scarcely be done here for the sake of conciseness.

3 The transcription, it must be admitted, is certainly influenced by the performance. Breaks in the recitation have mostly been deemed to mark the end of a line, as have rhyming words. Since rhythm and metre are barely considered in this analysis, however, their possible misrepresentation should not matter greatly. The animations in the video as well as the music have not been taken into consideration here, except for passages where the text is displayed as part of the animation. 


\subsection{The Approach of the Analysis}

The analysis of Storm's possible influence on the recipient's identity will begin with the establishment of a theoretical framework that describes how identity construction might work psychologically. This will include an examination of why people identify at all, what part of the mind identity comprises, how it is constituted, and how its formation can be influenced. Based on this framework, the relationship between the recipient and the text, particularly the narrator will be discussed and assessed.

Then, the influence of the narrative structure of Storm on the recipient's inclination to identify with elements of the text will be examined, following Petersens categorisation of the features of narrative systems. Here, especially the consequences of the narrator's positioning with regard to both the narrated and the recipient will be inspected, as well as the ways in which he narrator (who is both a character and the narrating medium) can be characterised by analysing his rendition of the story.

Following that, the capability of pleasure derived from art, particularly from poetry, to elicit the reader's identification with views expressed in Storm will be investigated on the basis of Bloom's ideas on the workings of pleasure. Furthermore, instances in the poem will be examined, where lyric devices (imagery, specifically) may serve both to illustrate thoughts and emotions represented in the text and to make the reader more open to identifying with those sentiments by displaying them in a pleasurable way.

Finally, conclusions about Storm's capability to influence its recipient's identity construction will be drawn and different approaches to how the text might be received and processed will briefly be envisaged.

\section{An Applicable Theory of Identity Construction}

\subsection{The Subject}

To analyse the effects of any text on a reader's processes of identification with characters or views represented in that text, a theoretical framework that shows how identity construction works is needed. To establish such a framework it is vital to consider what exactly identity formation is considered to be. Is it simply the social process of blending in with a certain group of people as sociologists may think? Is identity formed when agreeing or disagreeing with someone politically, as a political scientist might argue? Is it a result of education and socialisation, a temporary psychological state, or is it something inherent, transcendental like the soul perhaps - or simply genetic - and therefore unchanging? In this paper, the process

Naturally, knowledge of both the animations and of the music may have influenced the transcription subconsciously, yet to no extent that has been detected or appeared relevant. 
of identity formation will be viewed as a psychological process. This means that it takes place on the theoretical level of what will be called the subjects. For now, 'identity' ${ }^{5}$ will simply be deemed a certain state of mental organisation, since a more detailed definition of identity will be developed over the course of this chapter. The same applies to 'identification', which, until it is defined more thoroughly, shall simply denote the process of assuming an identity.

A precise, widely agreed-upon definition of what the term subject actually denotes does not seem to exist. According to Luke Ferretter, "the concept of the subject is one in which an individual human being is believed to be the independent origin of their own thoughts, actions and emotions" (88). Thus, it could be argued that every human being is psychically also a subject. This notion seems to be in accord with Louis Althusser's remark that the term "subject" has been used simply as a different name for what used to be called "soul" (Althusser 115-116), which further suggests that the subject is a unified entity and the very core of what constitutes a human mind.

But Althusser also remarks that a "concrete subject", which is always already a part of an individual human being, only becomes a proper, conscious subject when it is hailed or "interpellated" by what he calls "ideology" (118). He elaborates that the subject is somehow hailed by ideology just like someone on the street might be hailed by a police officer, and that this hailing leads to the subject gaining awareness of its own existence. This may sound confusing - especially because he describes this process as always having happened already, which in conclusion seems to mean that it never happens any more $^{6}$. But what is important for the analysis conducted in this paper is the notion that the subject may not just inexplicably exist with no origin in an unchanging form. The suggestion is that the subject is constituted or 'made', be it through Althusser's 'ideology' or otherwise. Since it has been implicitly presumed for the purpose of this paper that identity, too, is somehow formed rather than simply present (the object of study being identity formation), the constitution of the subject may well have an influence on identity construction - a possibility that should be kept in mind when the theoretical basis for a literary analysis of identity formation is compiled.

Jacques Lacan believes that the subject "does not function as the center of human thought and action, but [. . . inhabits the mind as an elusive agency, controlling yet uncontrollable" (Nobus 61). Lacan thus not only challenges the idea that the subject is the fixed core of the human mind, but also suggests that it should not be thought of as a unified entity or construct. He rather sees it as a

4 Italics will be used when a technical term is first introduced.

5 The inverted commas in this paragraph indicate that the word will be used as a loosely defined term, until its technical meaning is given.

6 Frankly, it seems as though Althusser either works with a few assumptions that he did not make apparent, or that some of the context of his musings has been lost in translation. Luckily, his concept of interpellation was reformulated by Stuart Hall and is in that form explained later in this chapter. 
loose, vague, largely unconscious "agency," a force that subtly influences human thoughts, emotions and actions.

However interesting Lacan's notion of the impalpable, "elusive" subject may be, not regarding the subject as a somewhat unified being would probably make for a very vague theoretical basis for an analysis of identity formation. If the subject were not unified and ascertainable, then how could it be affected by a text like Storm and how would one determine which mental processes it affects? Yet simply ignoring the idea that the subject may not exist purely in its own right could unnecessarily narrow the applicability of the theoretical groundwork for the analysis. Perhaps, then, a compromise can be found, which neither renders the concept of the subject inapplicable in a literary analysis, nor excludes the possibility that the subject may not be a unified, indissoluble, completed entity.

The relatively recent psychological theory of the 'dialogical self seems to provide such a compromise. In dialogical self theory (DST) the so-called self "becomes a "mini-society", more technically speaking a "dynamic multiplicity of I-positions" (Hermans and Gieser 2). This means that the self can be imagined as a space in which the $I$ and different I-positions exist ${ }^{7}$. Within this conceptual space of the self, the I "is able to move from one position to the other in accordance with changes in situation and time" (2), while "dialogical exchanges among positions can develop" (ibid.) as well. This means that not only the positioning of the I, but also the I-positions themselves can change and shift, making the self dynamic, yet unified as could be said of a society of people.

The idea of the subject or I and subject-positions or I-positions as being embedded in the self includes the notion that the subject is the core part of a unity (the self), yet still capable of radical change and multiplicity (occupying diverse, possibly even contesting subject positions). Therefore, these concepts of the subject and the self will be used as part of the theoretical framework for identity formation employed in this paper.

\subsection{The Need to Identify}

Now that a workable definition of the subject has been established, its role in the process of identity formation must be considered.

In everyday speech the use of the word 'identity' implies that a person or a group of people 'has' some sort of identity. This means that identity is always something that belongs to someone or is ascribed to them. By the same token, 'identification' (not in the sense of 'pass' or 'credentials') usually implies that there

For the purpose of this paper, "the I" will be considered to be synonymous with "the subject", since Stuart Hall uses the terms "subject" and "subject position" in his article on identity construction as well, but does not elaborate on the origin of his terminology. Links between Hall's terminology and DST may exist, but have not been researched in the context of this paper, because such specific inquiries into the history of psychoanalysis and psychology were deemed too extensive for establishing a theoretical basis for a literary analysis of Storm. 
is someone who identifies with someone or something, an 'identifier' who 'takes' an identity, so to speak. The aim of this paper is to examine how recipients of the text under consideration are influenced to identify or not to identify with the narrator. Hence, it seems reasonable to assume that in a theory of identity formation, too, there must be someone or something that 'has' an identity or undergoes a process of identification. Following Stuart Hall's notions on identity and identification, that someone or something will be considered to be the subject. However, the assumption that the subject is the part of the conceptualised mind that 'has' or readily 'takes' an identity implies that the subject is not only vaguely capable of assuming an identity or identities but that it has an inherent tendency or even a need to do so - otherwise, why would it assume one? In theories of personal identity and identification this need is often simply presumed to exist, perhaps because considering it a given seems commonsensical. Hall, too, does not seem to mention why identities arise and why identification occurs, but only how. It seems, though, that an analysis of how Storm influences its recipient's inclination to identify with either the narrator or Storm can hardly be conducted without at least a basic understanding of the need for identity. After all, that need could be precisely what is influenced within the recipient's mind by Storm.

A rather convenient explanation for the need for identification can be extrapolated from Judith Butler's claim that gender identity "is performatively constituted" (Butler 1990: 25). This means that gender identity formation does not entail intentionality or volition from the subject, but, more or less, simply 'happens' due to restrictions (regarding gender) of the language used by the subject to narratively construct its gender identity. A generalisation of Butler's explanation to include identity formation in general, rather than just the formation of gender identity, would hence state that identity is imposed onto the subject by the language of selfnarration. Justifiable as that thought might be, for an analysis of identification in Storm it would mean that the recipients' inclination to identify with the narrator or not to do so - entirely depends on each individual recipient's personal use of language for self-narration. This would make it almost impossible to make any generalising statement at all about the influence of Storm's literary properties on a model recipient, because every recipient would most likely be fundamentally differently affected by the text. Furthermore, while a subject may not intentionally undergo identification, the process still does take place and there still is no explanation what purpose it serves. The question of why identification occurs therefore remains.

In their article "The Need to Belong: Desire for Interpersonal Attachments as a Fundamental Human Motivation", Roy F. Baumeister and Mark R. Leary evaluate "a hypothesized need to form and maintain strong, stable interpersonal relationships [. . .] in light of the empirical literature" (497). In their inquiry they "found evidence for a basic desire to form social attachments" (520) and they conclude that "the need to belong can be considered a fundamental human motiva- 
tion" (521). Presumably, then, the subject's presumed need to identify is simply part of that innate human need to belong.

However, part of Baumeister's and Leary's hypothesis is that the need to belong is only fulfilled within a "temporally stable and enduring framework of affective concern for each other's welfare" (497). Consequently, the subject's processes of identity formation would also have to result in the assumption of temporally stable identities which contribute to the fulfilment of the need to belong with someone or something. If so, how can a relatively short text like Storm influence a recipient's identification process even though the text is probably not perceived frequently and despite its influence on the recipient - in all likelihood - not being as continuous as an interpersonal relationship 8 ?

Sigmund Freud claims that "identification may arise with every perception of a common quality shared with some other person who is not an object of the sexual instinct" (680). Thus, as it is the subject which identifies, the important question here is not whether or not assumed identities will be stable, but rather whether or not they appear to provide enduring stability to the subject. Because "identifications belong to the imaginary" (Butler 1993: 68) and identities "arise from the narrativization of the self' (Hall 4), the subject's inclination to assume a certain identity must depend on how stable that identity is imagined to be. The subject has no way of 'knowing' how stable an identity is going to be, so it is most likely to adopt one which seems to provide stability in the subject's 'imagination', regardless of whether it actually does, or not ${ }^{9}$. This way of looking at the subject's inclination to identify also makes it possible to examine potential influences of the literary properties of Storm on the recipient's tendency to identify or not to identify with the narrator and his views. For example, if a point of identification provided in Storm is somehow presented in a way that makes it seem stable and preferable to other potential points of identification, then the subject's affinity to that point may increase.

\subsection{The Mechanics of Identity Formation}

Having established what part of the mind of the recipient undergoes processes of identity formation (the subject) and what purpose such a process may serve (the fulfilment of an inherent need to belong) still does not explain how exactly the assumption of an identity might work. An important hint towards the functioning of identificatory processes can be found in the aforementioned quotation by Stuart Hall. He states that identities "arise from the narrativization of the self". If the "narrativization of the self" can be imagined as a constantly ongoing discourse

8 Unless, perhaps, one were to occupy oneself with Storm over a period of several months.

9 As already mentioned, Judith Butler, for instance, suggests that identities and identifications are performative. Speaking of the subject's "imagination" and the subject not "knowing" something is therefore only a way of clarifying why imagined stability is important and not to suggest any kind of intentionality based on reasoning within the subject. 
within the mind, it seems logical to conclude that identity formation, too, is never finished as a process and that "identity is never a fixed core" (Brah 142), but developing and changing. Homi $\mathrm{K}$. Bhabha notes that "identity is never an a priori, nor a finished product; it is only ever the problematic process of access to an image of totality" (51), which further suggests that identities are not only capable of changing occasionally, but permanently in the process of alteration, always being imagined and re-imagined.

Hall, who in his essay "Introduction: Who Needs 'Identity'?" presents a comprehensive theory of the mental mechanics of identity formation, states that identities and identification are widely seen among theorists "as a construction, a process never completed - always "in process"” (2). He also claims that identities are "constantly in the process of change and transformation" (4), and again it can be seen that identities are not stable, but can only ever provide an illusion of stability.

When put into context with the theoretical framework of the subject established so far, the notion of identity as being shifting and unstable suggests that the nature of identity is similar to that of the self: dependant on the positioning of the subject. Although Hall does not directly employ the concepts of dialogical self theory, he argues that "identities are, as it were, the positions which the subject is obliged to take up" (6), and he thus presupposes a spatial concept of the mind that is apparently similar to the one in DST. An identity can thus be described as the combination of the subject and all subject positions occupied by it, while identification is "a process of articulation" (3), meaning the attachment of the subject to a few specific, interrelated subject positions. It should be stressed again, though, that this attachment - this identification - is "a process never completed - always 'in process" (2). The changing and non-unified nature of identity thus arises from its dependence on the ever shifting identifications that constitute it. Similarly, identifications can be considered to be "in process" both because the subject positions they encompass, according to DST, can change and develop and because the subject may pick different subject positions to occupy as well. This means that some understanding of the external and internal influences that regulate identifications is required to examine what different aspects of Storm might reinforce or weaken the recipient's inclination to identify.

\subsection{Interpellation, Exclusion and the Other}

Any process of identification, Hall argues, is elicited through the "hailing of the subject by discourse", which he calls "interpellation" (6). Contrary to Althusser's use of the term, Hall's "interpellation" is not an effect of ideology, but of discourse, which means that what is really to be considered in the analysis of Storm is how specific literary and discursive practices can "hail" - or interpellate - the subject of the recipient to make it occupy specific subject positions. One factor that seems to influence the effectiveness of interpellation has already been named: the imagined stability of the subject positions which the subject might prospectively oc- 
cupy. Another variable apart from the imagined foothold that identities provide appears to affect the subject's inclination to identify as well.

Hall states that "throughout their careers, identities can function as points of identification and attachment only because of their capacity to exclude" (4). He elaborates that "they emerge within the play of specific modalities of power" and that they are "the product of the marking of difference and exclusion" (4), which suggests that any process of identity construction must also involve the exclusion of something that is explicitly not part of that identity.

Other theorists, too, have pointed out the crucial role which exclusion as well as the establishment of imagined hierarchies play in identity formation. Jonathan Rutherford, for instance, remarks that "it is within their polarities of white/black, masculine/feminine, hetero/homosexual, where one term is always dominant and the other subordinate, that our identities are formed" (10) and Bhabha argues that "to exist is to be called into being in relation to an otherness" (44). Consequently, one might assume that the potency of interpellation is increased if the prospectively assumed identity seemingly involves a stronger repudiation of that which is marked as different - the so-called other.

It could admittedly be argued that exclusion and differentiation do not influence the inclination to identify directly. Instead, quite possibly, rigorous differentiation from an imagined constant other produces a similarly constant relationship to that other. Since such a stable relationship must somehow be part of the self, its establishment also leads to the stabilisation of the self, which could then be seen as the ultimate cause of identification. Rutherford mentions that "it is the threat of the dissolution of self that ignites the irrational hatred and hostility as the centre struggles to assert and secure the boundaries, that construct self from non-self' $(11)^{10}$, and while this comment shows that exclusion to some extent matters because it leads to the stabilisation of the self, it also suggests that exclusion very prominently occurs even during the construction of the self, and hence during the shaping of identity. As the analysis of Storm will focus on the formation and assembling rather than just the preservation of identities, exclusion will be considered as a different effect of interpellation than self-stabilisation.

Particularly in the context of an analysis of Storm, notions of identity being constructed from difference provide an interesting view upon identity formation, since the narrator's and Storm's views are displayed as being mutually exclusive. Possibly, therefore, their identities are to some degree based on the exclusion of their respective other. Hall states that identification "requires what is left outside, its constitutive outside" (3) and that identity is constructed "through the relation to

10 Rutherford's "self", it should be pointed out, is not the self used in DST or in this paper, as his "non-self" seems to denote what here will be called the other. The crucial difference between the two conceptions of the term "self" is that the other here will be considered to be part of the self, while the "non-self" in Rutherford's terminology seems to be the opposite of and outside the "self". This difference in terminology does not change the fact that otherness - whether within or outside the self - serves to stabilise the self. "Centre" here seems to mean the subject, the core of the self. 
the Other" (4). Since the only account of the argument in Storm is given by the narrator, Storm and her views may come to represent such a constitutive outside or constitutive other to the reader as well. To examine how the narrator's biased portrayal of Storm may influence the recipient's inclination to identify with the narrator, it is necessary to locate the place of the other in relation to the self and the subject.

In DST "the other, as real, imagined or remembered, can be addressed as an $I$ position as part of an extended self' (Hermans and Gieser 8). In fact, the term "extended self" here denotes precisely such a concept of the self, where the other is not considered to be outside the self, in contrast to the "Cartesian self, which is based on a dualistic conception, not only between self and body but also between self and other" (3). If, as stated in the quotation above, the "other" denotes a subject position (or, possibly, a set of subject positions) within the self, however, then how is it different from other subject positions within the self? The answer is that the other, while part of the self, is explicitly not part of identity. In fact, as far as they have been defined in this paper, this is the main difference between the abstract concepts of self and identity: the self includes the other, identity specifically does not. Thus, the other denotes a subject position that cannot be occupied by the subject, unless an assumed identity is fundamentally restructured and a different other emerges. As identities are shifting and constantly revised, one other can presumably be substituted for another over time. To be able to apply the notion of the other as being excluded from identity in the analysis of Storm, it should prove useful to make a few practically oriented assumptions about the nature of the other.

Firstly, although Hermans and Gieser state that the other "can be addressed as an I-position" (8), it should be more appropriate to see it as a set of subject positions rather than just as one here. The reason for this assumption is that the narrator in Storm, it seems, is not simply critical of one feature of Storm, but of quite a few of them, for instance her tattoos (Minchin 23-27, 242-243), her opinion about the legitimacy of alternative medicine (85-94) and her alleged lack of consideration for the other people at the dinner party (62-72). Since the recipient's inclination to identify with the narrator's views may not depend merely on the demotion of one, but of several features ascribed to Storm, it seems reasonable to see each of those features as a separate subject position. After all, the presumed multiplicity of subject positions within the self allows for such an assumption.

Secondly, the other is not only that which is excluded because it is seen as contesting or even threatening to identity. There are also what Hermans and Gieser call "significant others [. . .] who play a role in one's self temporarily or for a longer period" and who "serve as promoter positions" (17). Such significant others serving as promoter positions can, for instance, include family members, teachers, friends and images of divinity (ibid.): entities that simply cannot be incorporated into identity because their otherness is a necessary condition for their existence. After all, one cannot, realistically, be one's own parent. To the recipient of Storm, the narra- 
tor may to some extent function as a promoter position, thereby being part of the other, yet not necessarily subjected to the establishment of "a violent hierarchy" (Hall 5) that places the recipient's identity above that part of the other. This observation further justifies the previously made assumption that the other consists of multiple subject positions. Moreover, it shows that while there are parts of the other that are pointedly excluded and seen as a threat to identity, there are also such parts that make up milder contrasts to it, merely facilitating "coherence and organization in the self" (Hermans and Gieser 17) and in identities by allowing an individual to realise the boundaries of his or her identity.

\subsection{Short Summary: Identity Formation}

Now that an adequate theoretical framework for the analysis of identity formation in Storm has been developed, it seems appropriate to sum up its most important points. The conceptual space of the mind in which identity is formed is the self, which is inhabited by the subject and subject positions that represent elements of an individuals mind: feelings, traits, pieces of knowledge, opinions, ways of thinking, relationships to others and connections to the environment. In order to stabilise and organise the self, the subject occupies certain subject positions, which leads to the constitution of an identity. The attachment of the subject to a particular set of related subject positions is called identification. Processes of identity formation are performative and identities are ever shifting and do not actually provide long-lasting stability for the self and the subject, but are nonetheless 'imagined' to do so. The more stabilising or constructive a subject position seems, the more likely it is to be identified with. Interpellation is the process of making the subject 'aware' of a potentially assumable subject position and making it likely that the subject will occupy it. Subject positions that are not or cannot be occupied are part of the so called other and can be strongly opposed, even contrary to identity - or simply distinct from the subject positions that are incorporated into identity. Certain parts of the other can influence the self as promoter positions and thereby help with the organisation and structuring of identity and the self, promoting or demoting certain subject positions (i.e. altering the effects of interpellation). The marking of the other as different serves the purpose of ascertaining the boundaries of identity and therefore furthers the constitution of identity.

\subsection{Narrator and Recipient}

Now that the theoretical structure of the mind, the aims, mechanics and strategies of identity formation and how they may apply to the relationship between the recipient and the narrative have been discussed, a few assumptions made about the model recipient in light of the analysis of Storm must be pointed out. 
Firstly, in the following analysis, only the recipient's conceptual internal space will be considered. Thus, neither the narrator himself, nor any other character occurring in Storm will be viewed as a subject within a self. This is due to the fact that, as Niklas Luhmann remarks, "from the perspective of each subject, every other one possesses merely a derivative, constituted, constructed existence" (Luhmann xli). The problem is that "every subject conceives of itself as the condition of all the others" (ibid.), which in context with the established terms underlines the notion that there can only be one subject within each self 11 . Consequently, the recipient's observation of the characters in Storm might enable him or her to deduce that they probably view themselves as subjects as well, but the reader himself can only see them as others ${ }^{12}$. Hence, the influence of Storm on the recipient is that of others on a subject, not of subjects on a subject.

Secondly, when speaking of 'the recipient's' perception of a text, this obviously involves a generalisation. However, despite the fact that every individual reader reacts to and experiences a text differently, this generalisation is, to an extent, justified, because, as Petersen states, no reader of a fictional text is identical to him- or herself as a real person (20). He elaborates that a reader becomes a "fictional reader" ("Fiktional-Leser", ibid.) ${ }^{13}$ when he or she enters the fictional realm of the text, which means that the reception mechanisms which the reader uses in the real world are replaced by those that function in the fictional world (ibid.). These reception mechanisms of the fictional world oblige the fictional reader to perceive everything within it as true (ibid.), because it cannot be established within the reader's mind if its entire design - everything that is said about it - is constantly doubted. Petersen also acknowledges that this does not mean that the real reader's individual personality is abandoned completely (21), and he accepts that the interpretation of a fictional text depends both on the recipient and the text itself (36). For instance, if a real reader of Storm is entirely opposed to the narrator's views and behaviour, he or she is unlikely to agree with him wholeheartedly within the fictional world, since it would mean the incorporation of part of the other into identity and, thus, a destabilisation and reorganisation of the self. Nonetheless, the factor that actually determines the reading of the text, Petersen argues, is the text itself and not the reading subject, because the fictional reader usually has little choice but to accept everything presented within the fictional world (which he or she is part of) as true (ibid.). This general acceptance of the fictional world as being true, which all fictional readers must have to some extent, justifies the assumption that certain effects of Storm apply to more than just a fraction of its recipients' identification processes.

11 Unless, perhaps, in certain cases of mental illness, where it seems as though multiple personalities inhabit one mind. That thought is speculative, however.

12 'Others' meaning different parts of the overall other in the recipient's self.

13 Unless a different source is stated, translations of Petersens terms are devised by the author of this paper and the respective original is given and referenced in parentheses. 


\section{How the Narrative and Narrative Techniques Elicit Identification}

\subsection{Time and Space}

This first part of the analysis of Storm will focus on the narrative system of the text. Petersen's book on narrative systems (Erzählsysteme) provides a thorough and useful basis for examining the narrative structure and its potential influences on the reader.

First of all it should be mentioned that, in accord with Petersen, the narrator will not be seen as identical with the author, but instead viewed as a part of the fictional world of the narration, a medium devised by the author (16). Hence, the author is the creator of the narrative structure of the text, but not part of it (16) and therefore not too important when the reception of a fictional text's narrative is examined.

Petersen states that one major property of fictional texts that allows the reader to identify with characters portrayed in them is the lack of time and place (8). This does not mean, of course, that the setting of a fictional text does not matter, but because the real reader becomes a fictional reader within the narrative system, he or she is automatically 'transported' to the time and place of the fictional world. Discrepancies between the reality of the reader and the fictionality of the text thus do not necessarily keep the reader from assuming the views of characters, because the reader's individuality is partially deleted (ibid.).

Petersen also mentions that this only works if the fictional world is described with the same linguistic signs as the real world of the reader (9). Thus, the setting of Storm in a London inner city "top floor flat" (Minchin 1) - no too specific type of flat, really - will probably be more readily recognised as part of the fictional world by western readers than a setting, e.g., in a yurt in the Gobi Desert. Storm is hence set in a both spatially and situationally imaginable environment in the eyes of most (western) readers which certainly facilitates their immersion into the fictional world, thereby also increasing their susceptibility to influences on processes of identification. Because the recipient can recognise the subject positions represented by the setting, they and other subject positions shown in the text are more readily incorporated into his identity (or excluded from it and therefore still constitutive of it through otherness).

The time of the events in Storm, quite like the spatial setting, does not seem too remote for contemporary readers to imagine. Admittedly, no specific date is mentioned in the text, but the reference to Michael Jackson (148), for instance, suggests that the story takes place sometime around the turn of the twentieth century. Furthermore, Storm is narrated in the present tense, which of course does not automatically imply that the text is set in the reader's real present, but at least gives the impression of relative synchrony with the real world and a sense of relevance to the reader. Petersen mentions several different capacities in which the present 
tense ("Präsens") occurs in (German) literature (21-30), but it seems that its use only has distinct effects when combined with other tenses to create a contrast of some sort.

In Storm, the tense of the narration does not change and therefore a more indepth analysis of how the use of the present tense influences the recipient will be omitted here. Suffice it to say that both the setting and the tense of the narration facilitate the fictional reader's orientation in the fictional world, making him or her more susceptible to other influences of the narrative.

For instance, the narrator remarks that Storm, "like her meteorological namesake" (Minchin 71), does not consider how her comments might annoy the rest of the people at the dinner party. Thus, he portrays Storm as being inconsiderate and impolite in the context of civilised company. If the setting were not a flat in contemporary London, however, but, for example, a tent in the camp of some ancient barbarian tribe, Storm's lack of consideration would presumably appear in a different light. In that case, the reader might not be certain whether Storm is disregarding the prevalent social etiquette or not and therefore hesitate to agree with the narrator's opinion that Storm is behaving rudely. The actual setting of Storm does not provide reasons to doubt the narrator's judgement to such an extent, and so, it serves to raise the recipient's responsiveness to interpellation by Storm.

\subsection{The Form of Narration}

\section{Forms of Narration and the Fictional}

Petersen categorises the components that make up narrative systems according to the different relations between the narrated, the narrator and the reader which they describe. He calls the ontic ${ }^{14}$ connection between the narrator and the narrated the form of narration (")Erzählform»", 53) and here distinguishes between the I-form, the he-form and the you-form (53-65). In Storm the I-form is used, because the narrator refers to himself as "I" and is a figure in the story, which means that the reader receives an overtly subjective account of the events. The I-form could thus simply serve to represent the narrator's view of the fictional reality as indisputably correct, since the reader, as mentioned before, generally has to assume that most of that which is said about the fictional world is true. Hence, if the narrator states that Storm's arguments for alternative medicine are invalid, then the reader can only doubt the truth of that statement by drawing upon his or her real life knowledge or

14 "Ontic connection" ("ontische Verhältnis", 53) seemingly means the relation in which the entities exist to each other (i.e. is the one part of the other or are they separate, perhaps even opposite?). The term is presumably employed by Petersen because he also describes other connections between the narrator and the narrated (for instance how the narrator is able to view the narrated, as opposed to where he stands in relation to it). The exact meaning of the term was deemed inconsequential for this paper, since it becomes clear from Petersen's text what exactly he means by form of narration, and since the term does not reoccur to any noteworthy extent. 
opinion on the matter (or by finding signs within the story which reveal that the narrator may be wrong).

Within the realm of the fictional, the narrator's descriptions and judgements mostly remain uncontested as long as they are not logically flawed or otherwise challenged inside the fictional world. Indeed, as long as the I-narrator in Storm does not gravely undermine his own credibility, the reader cannot contest his account without referring to the real world and thereby also disrupting the perceived fictionality of the text. Consequently, he or she would presumably cease to be a proper fictional reader, because the fictional reader is part of the fictional world that is then subverted.

On the level of the reader's self, the denial of the fictionality of the text could mean that some element of it may have been deemed a threat to the recipient's understanding of the real world (and to his or her current identity) and that whatever it was that unsettled the reader is part of his or her other. It can thus be said that if an element of the fictional world of Storm is recognised by the recipient as being a part of his or her other, identification with that subject position is unlikely to occur. Instead, perhaps, the text must promote subject positions which are either already loosely incorporated into the recipient's identity or which are created while reading. For instance, someone who reads Storm might be rather religious and spiritual like Storm is, yet unaware of the narrator's notion that "Science adjusts its views based on what's observed" (Minchin 164), while "Faith is the denial of observation so that belief can be preserved" (165). Hence, this statement by the narrator will presumably not make the reader stop being religious, but it could make him or her aware of the idea that some religious people can be bigoted. This might make the recipient consider him- or herself to be religious, still, but specifically not in a bigoted way. Thus, hypothetically, the new subject position of 'not being bigoted' or maybe of 'being open-minded' might arise and become a part of the reader's identity.

\section{The Experiencing I and the Narrating I}

The problem that elements of the fictional world may represent parts of the recipient's other and therefore be unavailable for incorporation into his or her identity is not necessarily a unique effect of the I-form of narration, but could arise in a particularly biased narration in the he- or you-form as well. What is distinct about the I-form, Petersen argues, is that it renders both the narrating I and the experiencing I recognisable (56). This distinction is particularly prominent when an I-narrator tells a story that lies in the past and comments on it from a later perspective, as Petersen demonstrates (56).

Although Storm is narrated in the present tense and although most of the account seems to be given from the perspective of the experiencing I, it could be argued that the duality between narrating and experiencing I can be spotted here as well. After Storm releases a tirade of spiritualist arguments which are dismissed as 
"vacuous crap" (Minchin 123) by the narrator, he speculates, "Maybe it's the Hamlet she just misquothed / or the fifth glass of wine I just quaffed, / but my diplomacy-dyke groans / and the arsehole held back by its stones / can be held back no more." (124-128) While it is possible that the notions of the "diplomacy-dyke" and the "arsehole held back by its stones" are part of the way the experiencing I perceives and processes the situation at the time when it occurs, the reflections upon the cause of the outburst that follows - Storm's misquoting of Shakespeare or the excessive consumption of alcohol - seem like additions made by the narrating I. Considering that the experiencing $\mathrm{I}$ is described as being absolutely stunned and infuriated by Storm's words, not to mention intoxicated by the wine, it simply seems unlikely that he would be able to reflect so soberly upon the cause of the rant which he is about to release. There can be no certainty, of course, as to whether these sentiments originate from the experiencing I or the narrating I, but at least it becomes clear that this passage and others like it are ambiguous when it comes to the bipolarity of the I-narrative.

The capacity of the I-narration to show both the experiencing I's and the narrating I's perspective and evaluation of events in the story may have significant effects on the recipient's inclination to identify with the narrator. It could be argued that the I-narration appears to be more objective than even a he-narration which displays only the perspective of one character. Thus, if the I-narration shows events both from the perspective of the experiencing I at the time when they take place and from the perspective of the narrating I at the time when the story is narrated, then the former perspective may seem more subjective, but the latter will probably seem more considered and self-reflective. After all, it is still the same person speaking, but presumably at a later time, and the narrating I can potentially provide thoughts on a situation which the experiencing I may not have had when that situation occurred. This degree of self-reflection - self-evaluation even - exhibited by the narrating I may make the narrator seem more sincere and trustworthy, which is why instances where the narrating I can be detected can make the narrator appear more reliable, honest and objective to the reader. As this effect is made possible only in the I-form, it can be concluded that this form of narration helps to firmly ground the fictional reader in the fictional world and to encourage his or her acceptance of the it, thus making him or her more prone to incorporate subject positions presented in the text into his or her identity.

\section{The I-Form in Storm}

As mentioned before, there is the problem in Storm that the narrating I never appears to occur indubitably, but only ever in ambiguous instances. However, it also seems as though the I-form's trust-enhancing self-reflectivity can still emerge, since a sense that the narrating $I$ is potentially self-observant and somewhat critical towards its own actions is likely to come across nonetheless. 
The narrator notices, for instance, that his hostess throws him a warning glance to make sure that he does not burst into one of his "rare, but fun, rants" (Minchin 62-64). Although this particular piece of self-description may seem rather selfsatisfied, it still shows that the narrator - either as the experiencing or narrating I is by no means unaware of his shortcomings, which makes his account seem more honest, if in this case perhaps also a little self-congratulatory.

Another similar example can be seen when he casually describes an utterance which he makes at an early point during the dinner party as "some un-hippily empirical comment" (37-38). Storm is previously in the text described in a way that may suggest that she is a hippie (22-31), but it does not seem as though the narrator is convinced of this or aware that his comment is pointedly "un-hippily" when he makes it. At the time, he presumably simply stated his opinion and only became aware of his comment's "un-hippily" nature once he noticed that Storm disagrees with him, which would indicate that it is the perspective of the narrating $I$ that is given here, rather than that of the experiencing I. Neither does he describe more specifically what his comment entails which may indicate that he does not even remember it in sufficient detail. Again, this would suggest that the view of the narrating $I$ is presented which, due to its self-reflectivity, makes the entire narrative seem more thoroughly thought through and reliable. This facilitates the recipient's potential identification with subject positions presented in the text, since it also makes those subject positions seem reliable and stabilising in the recipient's imagination.

A problem with the assumption that the time of events precedes the time of narration in Storm is of course that the text is narrated in the present tense, which seems to indicate that the time of the events and the time when they are narrated are the same. Realistically, however, one would also intuitively assume that the narrator cannot be part of the events and recount them at the same time (except while writing a diary, perhaps), and Petersen states that the epic present tense has the same function as the epic past tense (24). Hence, the notion that the experiencing I's perspective is an earlier one than that of the narrating I seems appropriate here.

\section{Personality}

One further aspect of the form of narration mentioned by Petersen is that the more subjective the narration is, the more prominent the personality ("Personalität") of the narrating I becomes (59). In Storm, as demonstrated, the narrating I does not figure very prominently and thus does not actively comment on the events, even though it becomes apparent enough to indicate some self-reflection on the part of the narrator. The account therefore seems somewhat neutral and factual and not as if the narrator was trying to impose his opinion on the reader.

Later in the poem, of course, the narration consists mostly of the experiencing I's direct speech, which is directed at Storm, but perceived by the reader as well. 
Thus, the experiencing I's opinion may still be imposed on the reader, but since the narrating I (who is closer to the recipient than the experiencing I, because he is the medium who relays the information) does not have such a direct influence, it presumably does not make the recipient uncomfortable by trying to force an opinion on him or her. A more urging attitude towards the reader and a more overt personality of the narrating I might contest the reader's identity to a degree where identification with the narrator's viewpoint would be prevented because it would be perceived as a threat to the stability of the recipient's self. Interestingly, many of Storm's comments quoted by the narrator seem far more absolute and forward than the narrator's account, which may cause the reader to perceive Storm's views as a threat to his or her identity rather than the comparatively mild seeming narrator. When the narrator begins to quote himself as an acting character later in the text, this impression might shift to some degree, as he, too becomes quite urgent and offensive.

It will hopefully have become apparent in this section, that the form of narration in Storm - the I-form - serves to make the narrator seem reliable and honest in his account, thereby increasing the recipient's inclination to incorporate the narrator's views into his or her identity as subject positions. It could therefore be seen as a tool to establish the narrator, who is an other in the self of the reader, as a promoter position that is able to influence the organisation of the recipient's self and identity.

\subsection{The Narrator's Point of View}

According to Petersen, the form of narration describes the connection between the narrator and the narrated (53), and so does the point of view of the narrator ("Standort des Erzählers", ibid.), but on a spatial and temporal level. Petersen also makes mention of the issue that in the English-speaking world the term 'point of view' is often used to refer to a mixture of the narrator's point of view, the narrator's perception ("»Sichtweise «", 65) (i.e. his/her capability to perceive the thoughts and emotions of characters) and sometimes even the narrator's behaviour ("Erzählverhalten", 68).

To some extent, the point of view in Storm has already been discussed, as it has been assessed in chapter 3.2 that Storm is presumably narrated slightly after the events have actually taken place. Thus, the temporal relation between the narrator and the narrated can be described as very close, but not quite synchronous.

As for the spacial distance, it has also already been pointed out that the difference between the narrating and the experiencing I is rather small and mostly ambiguous, so that the narrator is more or less identical with himself as a figure in the story and therefore very close to the happenings. This limits his overview in comparison to an omniscient he-narrator, of course, and because only the narrator's own narrow point of view is shown, it is difficult for the reader to consider the events from Storm's angle other than by interpreting the narrator's rendition of her 
behaviour and utterances ${ }^{15}$. Consequently, the point of view of the narrator makes it harder for the reader to identify with Storm's opinions, since the reader shares the perspective of the narrator and therefore observes Storm as being opposite him- or herself and possibly even as being part of his or her own other. Thus, the point of view in Storm supports the exclusion of the subject positions represented by Storm and furthers the instalment of the narrator as a promoter position within the recipient's self by putting the reader in the narrator's position.

\subsection{The Perception of the Narrator}

Petersen's category of the perceptions ("Sichtweisen", 67) of the narrator has a similar effect as the point of view, because it concerns the capability of the narrator on the one hand to describe the outer appearance of characters and on the other hand to relay their thoughts and feelings to the reader (67).

In Storm the narrator is only capable of perceiving his own inner state of mind, which, considering that he is an I-narrator, makes sense. Admittedly, Petersen mentions cases where an I-narrator is also aware of the thoughts of others (67-68), yet in Storm the thoughts of other characters are not represented in their unaltered form, but only as the narrator's interpretations of their actions. For instance, after Storm counters the narrator's "unhippily empirical comment" (Minchin 37-38), his wife "widens her eyes" (41), silently begging him to "be nice" (42), which shows that he does not actually render her thoughts, but only non-verbal communication between her and him. Similarly, when he states, "My hostess throws me a glance / she, like my wife, knows there's a chance / I'll be off on one of my rare, but fun, rants" (62-64), he does not seem to be able to describe her thoughts without receiving any external input from her to interpret. Although similar examples lead Petersen to assume that an I-narrator can also relay the inner lives of other characters (68), it is still clear that he or she has to conclude them from those character's actions. The sentiments are thus filtered through the narrator's subjectivity and therefore by no means reliable; possibly they are only phantasms of the narrator.

By only describing his own thoughts and feelings, the narrator makes it easy for the reader to empathise with him, but difficult to comprehend the motivations of other characters, especially those of Storm. The reader thus has a chance to understand and evaluate the reasons behind the narrator's actions, while Storm's motives (beyond her direct comments) remain obscure. Therefore, assuming Storm's views, or - more specifically - occupying the subject positions represented by them, will seem unproductive to the reader because they do not appear to be able to provide his or her identity with any stability or organisation due to their vagueness. Of course, large parts of the text consist of direct speech by both the narrator and Storm, so that it could be argued that Storm's motivations are to

15 Naturally, the narrator may also choose to withhold certain information, but this eventuality will not be considered here for the sake of brevity. 
some degree represented in that form. Nonetheless, as long as the narrator only reports his experience without quoting Storm, he never even speculates as to what might be driving her.

The rendering of the events at the dinner party through the narrator's subjective perception thus furthers his establishment as a promoter position in the recipient's self. Making Storm's motivations seem hard to comprehend, perhaps even incomprehensible also supports the exclusion of the subject positions she represents into the reader's other, while the subject positions favoured by the narrator are promoted. Consequently, the narrator not only installs himself as a promoter position, but already acts as one in manipulating Storm's image in the recipient's mind and in enforcing the interpellation of his preferred subject positions.

\subsection{The Narrator's Behaviour}

The category of the narrator's behaviour ("Erzählverhalten", Petersen 68) encompasses exactly what it says on the tin: it is the manner in which the narrator presents the narrated (68). It should be emphasised that this does not involve the attitude of the narrator towards the narrated, but only the question: does he or does he not evaluate and comment on the narrated, does some kind of subjectivity take effect in the narration? The three kinds of behaviour suggested by Petersen are authorial ("auktoriale"), personal ("personale") and neutral ("neutrale") behaviour (68). Neutral behaviour essentially means that the narrator neither comments on the narrated nor assumes the perspective of a character (74). The narrator in Storm is clearly not neutral, since he is actually one of the characters in the narrative and overtly subjective in his account. Hence, he must be authorial or personal.

Authorial behaviour means that the narrating medium can intervene in the narration to comment on or to assess characters, situations and other elements of the narrated (68). In Storm, this seems to be the case insofar as the narrator certainly does not reserve judgement on Storm. This being said, personal narrative behaviour may involve commentary as well, but only such that it renders the perspective of a figure in the narration, not that of the narrating medium (69). This, too, could to be the case in Storm, as the I-narrator is both the narrating medium and a character. Hence the problem prompted by Storm is once more the uncertainty whether or not narrating and experiencing I can really be separated. It has already been assumed in chapter 3.2, however, that the narration and the events do not take place synchronously and hence that the narrating I can indeed be distinguished from the experiencing I. The narrator must therefore rather be regarded as authorial, because he comments on the happenings from a subsequent and non-figural perhaps 'post-figural' - perspective.

Concerning the reader's potential identification with subject positions represented in the narration, the narrator's authorial behaviour allows for a crucial effect: it enables the narrator to address the recipient fairly directly. Whenever the narrating I comments on the narrated, that additional information is relayed to the 
reader and influences the way he or she evaluates the narrated. The narrator in Storm - as the narrating I and not the character - can thus attempt to lure the recipient into sharing his views by demoting the subject positions assigned to Storm and by elevating those represented by himself.

For instance, by mentioning that Storm, "like her meteorological namesake" (Minchin 71), does not seem to be concerned about the atmosphere at the dinner table (a comment which could be attributed to the narrating I), the narrating medium tries to convey to the reader that Storm is inconsiderate. It is also said that the narrator himself has "no intention of rocking the boat" (69), which presents him as being more socially aware and therefore superior to Storm. Similarly, the narrating I's allusion to his "rare, but fun, rants" (64) significantly takes the edge of the notion of a prospective defiant tirade against Storm, possibly even making the reader curious to know what such a rant might entail and why it might be "fun". Thus, the narrating I attempts to make what may objectively be considered rude behaviour (i.e. ranting) seem acceptable, even enjoyable, when he himself exhibits it, whilst at the same time depicting Storm's demeanour as reckless and anti-social.

On the level of the reader's self, this means that the narrating medium as a promoter position 'promotes' the subject positions represented by the experiencing I to elicit or reaffirm (depending on whether or not they are already occupied by the subject) their incorporation into the recipient's identity. This 'promotion' of certain subject positions means that the interpellation of the subject is augmented in such a way that the subject's affinity to them is increased.

As assessed in chapter 2, the two main factors that influence interpellation and the subject's inclination to occupy certain positions are the imagined stabilising effects of those positions and their capacity to exclude. In the case of Storm's alleged lack of consideration, it seems that mainly the latter takes effect, since the narrating I points out the difference between himself and Storm. By authorially disparaging the subject positions represented by Storm, the narrator causes the exclusion of those subject positions from the recipient's identity and hence, by implication, their integration into his or her other. Since the narrator represents the opposite of Storm's positions in the duality of 'considerateness' versus a lack thereof, his positions cannot be part of the reader's other as long as Storm's are, and must therefore be incorporated into identity (assuming that the reader is indeed influenced by the narrating I's interventions). Hence, the authorial narrative behaviour enables the narrator to display circumstances and characters in ways that to a considerable degree alter the recipient's conception of them including his or her tendency to identify with them. 


\subsection{The Narrative Attitude}

\section{The Attitude towards Characters}

To some extent the narrative attitude ("Erzählhaltung", Petersen 78) has already been touched upon in the previous chapter. While the category of the narrator's behaviour only describes whether or not and from what perspective the narrator comments on the narrated, the narrative attitude encompasses the narrator's posture towards the narrated (ibid.). A neutral narrative attitude thus means more or less the same as neutral behaviour: that the narrator does not express or show any kind of sentiment, but simply relays factual information and direct speech to the reader (ibid.). Since the narrator in Storm is obviously biased, he most certainly cannot be considered neutral.

Petersen states that a narrator's attitude towards the narrated, towards characters and their thinking and demeanour can be affirmative or dismissive, critical, sceptical or varying, and that it may occur to a varying degree of sophistication and clarity (ibid.). It is not only expressed in authorial interventions, but can also be extrapolated from other stylistic devices used by the narrator, for instance if a particularly ironic narrating style is assumed (ibid.). Hence, both the narrative attitude and the way it is articulated must be considered on the basis of the linguistic devices used by the narrator.

In Storm, as has already been shown, the narrative attitude can to some extent be seen in the authorial interventions by the narrating I, which are made to subtly disparage Storm and to promote the narrator's views. However, the rest of the narration is very subjective as well and comments are also made from the figural perspective of the experiencing I. For instance, the narrator mentions that "Conversation is initially bright and light-hearted, / but it's not long before Storm gets started" (Minchin 32-33), suggesting that it was to be expected that Storm would become annoying at some point. His attitude towards Storm is thus not only dismissive, but prejudiced as well, as he already anticipates her supposedly reckless behaviour. The narrator's attitude remains pejorative of Storm's allegedly stereotypical, anti-scientific arguments throughout the narration and he later compares her to a "sniper using bollocks for ammunition" (155), which also shows that his language becomes more derogatory in his later descriptions of her.

After Storm states that "You can't know anything, / knowledge is merely opinion" (34-35), the narrator discloses his "urge to ask Storm / whether knowledge is so loose weave / of a morning, / when deciding whether to leave / her apartment by the front door, / or the window on her second floor" (45-50), thereby sarcastically dismissing her utterance and even casually raising the idea of her being injured in a fall. It can thus be seen that the narrator expresses his attitude towards Storm far less subtly when he narrates from the perspective of the experiencing I. 
Since the reader, particularly on this occasion, is aware that the described sentiments belong to the experiencing I who has to resist the urge to express them, it becomes clear that these notions are very subjective. It could hence be argued that the narration seems to be rather undifferentiated which would make the narrator seem unreliable and potentially decrease the reader's inclination to share his views (unless he or she does so already and is amused by the remark). However, other readers too may recognize the experiencing I's internal response to Storm's claim as valid, since Storm - despite her disbelief in the existence of knowledge - is presumably indeed certain that leaving a second floor flat by the window instead of the door is impractical, possibly even dangerous. Furthermore, at this point in the narration recipients may have noticed (as pointed out in chapter 3.2) that one can also see the slightly more objective narrating I in Storm, which to some extent has the capability to retrospectively re-evaluate the narrated. As the narrating I in no way seems to intervene to mitigate the experiencing I's harsh thoughts, it appears as if the narrating I yet approves of them. Within the fictional world, the notion of Storm falling out of the window is thus rendered somewhat acceptable and does not necessarily lower the recipient's tendency to share the narrator's opinions.

The narrator's attitude towards himself - he is, after all, also part of the narrated as a character - is of course rather approving, but he also shows a certain degree of self-irony when it comes to his irritability in the face of what he perceives as Storm's ignorance and naivety. This can be seen in the examination of his supposedly "rare, but fun, rants" (64) in chapter 3.2, but also in his confession that he labels Storm as belonging to a group of people whose values he repudiates:

And when she says: "I'm sagittarian", I confess a pigeon hole starts to form and is immediately filled with pigeon when she says her name is 'Storm'. (28-31)

The narrator, thus, does not attempt to hide his prejudice from the reader and seems to articulate his attitude toward himself very openly and honestly which probably makes him seem like a fairly decent person in the recipient's eyes.

\section{Self-Subversion of the Narrator}

It has already been stated that the narrator keeps pointing out Storm's alleged inconsideration, whilst describing himself as being careful to bite back his annoyance at Storm for the benefit of the general mood at the dinner party. Hence, it seems that leading up to his rather rampant argument with Storm later in the poem, he feels that he has to justify his increasingly unrestrained reactions to her allegedly anti-scientific propositions. For instance, he states: 
And although Storm is starting to get my goat,

I have no intention of rocking the boat.

Although it's becoming a bit of a wrestle, because like her meteorological namesake

Storm has no such concerns for our vessel. (68-69)

He clearly does not take responsibility for his inability to pull himself together, but blames Storm for it, which suggests that he is aware of his lack of self-restraint but unwilling to admit to it. Assuming that this is the case, the reader may get the idea that the narrator is less sure of himself and of the views he holds than he seems on the surface. This might bring on doubts about the validity of his standpoint and decrease the recipient's inclination to identify with him. In other words, the subject positions represented and promoted by the narrator may seem less stabilising and justifiable, and the recipient's subject's affinity to those subject positions might falter. This also shows that if the narration in Storm is deconstructed in a certain way, instances where interpellation can actually cause the subject to turn away from the narrator's subject positions can also occur.

As shown in the previous paragraph, the narrative attitude can also be employed to draw conclusions about the narrator himself, as "every explicit statement about another character is also an implicit (often unconscious) instance of selfcharacterisation" (Nünning and Nünning 107). An even more detailed analysis of what character traits of the narrator can be derived from the narrator's attitude will be refrained from here, as it would go beyond the aim of this paper. Suffice it to say that it may indeed be possible to deconstruct more narrative features than just the narrative attitude in Storm in such a way that the narrator's position is substantially undermined.

\subsection{Modes of Representation}

\section{The Modes in Storm}

Modes of representation ("Arten der Darbietung", Petersen 80) are the different uses of language which the narrator employs to relay the narrated (ibid.). This includes the narrator's account ("Erzählerbericht", ibid.), free indirect discourse ("erlebte Rede", ibid.; translation from Nünning and Nünning 189), indirect speech ("indirekte Rede", Petersen 80), the interior monologue ("inneren Monolog", ibid.) and the dialogue or direct speech ("Dialog bzw. [. . .] direkte Rede", ibid.). As for the narrator's account, Petersen specifies that it may contain descriptions, but also hints and foreshadowing as long as the narrating medium speaks and the information refers to the narrated rather than to the narrator or the reader (ibid.). Petersen also points out that it can be difficult to differentiate between the narrator's account and free 
indirect discourse, but is of the opinion that the context usually helps to determine which mode of representation is being used (ibid.).

In Storm, the prevalent modes of representation seem to be free indirect discourse and direct speech, although there are quite a few instances where - due to the uncertainty if the narrating I's or the experiencing I's perspective is rendered it is hard to tell whether an account, free indirect discourse or even an interior monologue is at hand. Direct speech is, of course, easily identifiable ${ }^{16}$, and indirect speech does not seem to occur at all in Storm $^{17}$.

The difficulty of distinguishing between an account, free indirect discourse and interior monologue already arises in the first few lines of Storm:

Inner north London, top floor flat,
all white walls, white carpet, white cat,
rice paper partitions,
modern art and ambition,
the host's a physician,
bright bloke, has his own practice,
his girlfriend's an actress,
an old mate of ours from home
and they're always great fun,
so to dinner we've come. (Minchin 1-10)

Vera and Ansgar Nünning name "the omission of all verbs of thinking and feeling, the complete removal of any mediating instance from the narrative" and "the presentation of the character's mental processes in his or her language" (126) among the characteristics of the interior monologue. While these criteria mostly seem to apply, the "removal of any mediating instance from the narrative" is no longer given in the last line: "so to dinner we've come" (Minchin 10). The implication of the pronoun "we" is that there is an I-narrator (or at least - rather unusually something like 'we-narrators') and considering the fact that there also does not seem to be a complete "omission of punctuation" (Nünning and Nünning 126), it seems unlikely that an interior monologue is really the case here ${ }^{18}$.

16 If direct speech is considered to be the rendition of utterances in their exact wording in quotation marks, as it is here.

17 Indirect speech is here considered to be the indirect, yet faithful rendition of characters' direct statements by the narrator. However, whenever a character in Storm makes an utterance, the information is either relayed as direct speech (i.e. directly quoted by the narrator), or omitted and just hinted at. Hence, indirect speech does not seem to occur, unless, perhaps, one could spot it somewhere with considerable interpretative effort.

18 Of course, the punctuation in Storm cannot be extrapolated from its performance, which means that punctuation may indeed be left out here. Nonetheless, the occurrence of the pronoun "we" will be seen as a sufficient reason for dismissing the notion that the respective excerpt could be an interior monologue. 
Much rather, the occurrence of a narrator suggests that the quoted excerpt from Storm is a narrator's account, albeit syntactically modified. Petersen's specification that an account is concerned with the narrated rather than the narrator himself or the reader (80) also seems to apply to the quoted passage, as the narrator indeed barely shows himself and as the reader is not addressed in any way. However, the issue of whether or not the account is given by the narrating or the experiencing I arises. The speaker clearly states, "we've come", which implies that 'they' have now arrived in the previously described setting and that the experiencing I's perspective is conveyed here. This impression is supported by the fact that the entire passage barely contains any personal pronouns or verbs, which suggests that an experience rather than an organised narration is rendered. Admittedly, Petersen acknowledges that no specific stylistic qualities are linked to a narrator's account, but he also mentions that the narrative must be presented by the epic medium (80). Since the I-narrator can occur in the capacity of both the experiencing and the narrating I, he can only be fully recognised as the epic medium in the form of the narrating I otherwise he only appears as a figure in the narrated. In the aforementioned quote from the beginning of Storm that does not seem to be the case. Thus, describing the passage as an account is inappropriate as well.

Free indirect discourse, bearing some resemblance to the interior monologue, means that "the character's thoughts and feelings are generally reported in his or her own language" (Nünning and Nünning 125). Furthermore, "free indirect discourse attempts to convey the illusion of offering an immediate insight into the perceptions and internal processes of a character." (ibid.) This certainly seems to be the case in the beginning of Storm and the "loose syntax" and "signals of subjectivity" (ibid.) also seem to be given, because it is clear that the rendered thoughts and evocations belong to the experiencing I, who is also part of the action. For these reasons and because both the interior monologue and the narrator's account have been discarded, the mode of representation in the beginning of Storm is free indirect discourse.

Indeed, there seems to be an alternation of free indirect discourse and (on fewer occasions) narrator's account throughout the rest of the poem - apart from the passages that are dialogue (i.e. direct speech), that is. As mentioned before, Petersen recognises that it can be hard to tell the two alternating modes apart, yet also remarks that the prevalent mode is most often easily discernible when considering the given context (80). But once more the difficulty in Storm is that the context in many instances allows for differing interpretations, because the I-narrator's bipolarity between experiencing and narrating I is only vaguely perceptible. Generally, it seems that the experiencing I's perspective is given, which suggests free indirect discourse. However, the few examples where the narrating I's view appears to be rendered (see previous chapters) could well be seen as narrator's accounts and the fluctuating perceptibility of the narrating medium seems to be the only way to determine which mode really is at hand - hence the ambiguity. Nonetheless, the 
possible effects of the prevalence of account and free indirect discourse on the recipient's inclination to identify can be examined.

\section{Effects of the Modes}

Petersen states that the perspective of the narrator and character merge in free indirect discourse (81). In the I-narration of Storm this is more or less the case already, since the narrator is a character. However, the fact that the narrator could also just render an account rather than the perspective of the experiencing I, yet chooses not to do so, suggests that the narrating and the experiencing I are, at large, in agreement. Thus, the combination of the two modes of narration (of which free indirect discourse is prevalent) further underlines that the relationship between the narrating I and the experiencing $I$ is rather harmonious. This suggests that the narrating I, which, as has been established in chapter 3.2, seems to have a more reflected and objective view of the events, shares the experiencing I's attitudes and opinions. Hence, the narrating I's apparent objectivity is to some extent transferred to the perspective of the experiencing I, potentially making its view seem less subjective and less specific to the narrated situation. The recipient might then perceive the narrator's thoughts and feelings as more sober and profound, and become more inclined to incorporate the seemingly stabilising and wellgrounded subject positions which they represent into his or her identity.

The interplay of free indirect discourse and narrator's account is at first only interrupted in the few cases when Storm is quoted in direct speech, for instance when she claims that "the human body is a mystery! / Science just falls in a hole / when it tries to explain the the nature of the soul!" (Minchin 59-61). These exclamations in direct speech can come across as somewhat disruptive of the narrator's rendition of the events, which may subtly cause the reader to become slightly annoyed at Storm. Thus, the narrator's insistence on the use of free indirect speech and account may also serve to make Storm's comments more noticeable by way of contrast and, perhaps, more unnerving. The reader would then presumably be more inclined to dismiss Storm's views and to accept those of the narrator.

Another interesting aspect regarding the use of modes of representation in Storm is that over the course of the poem there is a shift from the narrator's recount of the happenings towards more and more direct speech by the narrator and, to a lesser extent, by Storm. With regard to the plot, this is due to the circumstance that the narrator at first only describes the setting and his internal struggle to remain calm when confronted with Storm's opinions. When Storm keeps making remarks which the narrator finds increasingly preposterous and unjustifiable, he begins to counter her claims and his initially careful argumentation gradually becomes more unrestrained and defiant, culminating in a vigorous rant that is en- 
tirely rendered in direct speech ${ }^{19}$. Thus, the narrator as a narrating medium so to speak hands over the narration to the narrator as a character over the course of the text $^{20}$.

This development may play a significant role for the identity formation of the reader. As mentioned, the use of free indirect discourse and narrator's account in the beginning of the poem makes the reader more open to identifying with the narrator's views, because they seem rather moderated and not too urging. The assertions and opinions which the narrator expresses in direct speech, however, are rather direct. Hence, the recipient presumably perceives them as quite pressurising even though they are levelled at Storm. The earlier, 'milder' passages in free indirect discourse and as narrator's accounts could thus serve to somehow align the reader's views with those of the narrator to such an extent that the later, bolder argumentation will more readily be accepted by the recipient. Also, the fact that the criticism in the rant is directed at Storm rather than the recipient maybe takes the edge off it slightly, so that it may not seem quite as vile to the reader as it presumably does to Storm, its direct target.

On the level of the self, the gradually changing influence of Storm on the reader's identity could be interpreted in the following way. At first, when free indirect discourse and narrator's account are dominant in the narration, the subject positions that are represented and promoted by the narrator are established and incorporated into the reader's identity. Later, when direct speech prevails, the then reformed identity of the reader is asserted and secured through the forceful exclusion of the subject positions represented by Storm. The narrator functions as a promoter position in both steps, first increasing the reader's subject's inclination to occupy the promoted subject positions and then supporting the organisation and stabilisation of the newly articulated identity. By the end of the reading of Storm the recipient, if this development really does take place ${ }^{21}$, may thus largely agree with the narrator.

19 As the text of Storm was transcribed from a performance, parts of the unrestrained speech could theoretically also be seen as interior monologue rather than direct speech. The choice not to do so in the transcription is based on the circumstance that the performance as well as the text itself seem to suggest that the narrator is in fact talking to Storm and not to himself (there seems to be an addressee for the rant).

20 Of course, the term 'narration' then becomes less appropriate, because the rant contains criticism rather than events. Nünning and Nünning define the term as a "superordinate account of $[. .$. events on the [...] extradiegetic level" (192), wherefore the delivery of the tirade by the narrator as a character makes it even less of a 'narration'.

21 There may be other possible developments within the reader, which will be omitted here for the sake of brevity. 


\subsection{Styles}

Petersen's styles ("Sprachstile", 81) are the manners in which an author lets his or her narrator and the characters speak (81). Petersen claims that "the more I-ish" ("je ichhafter", 83) the narrative is, the more individual and colourful the style of the narrator is. This also means that the narrator can be characterised by examining the way he or she speaks (83). In Storm, however, the entire narrative is also a poem and Petersen's only considers styles with respect to narrative and not lyric texts. Thus, the adequacy of applying Petersen's notions to poetry is doubtful, yet disregarding his ideas at this point may be rash, so a few observation shall be named.

The narrating and the experiencing I's styles do not seem to differ fundamentally. However, the experiencing I's direct speech, especially towards the end, seems more crude than the narrating I's rendering of the happenings. Since the experiencing $\mathrm{I}$ is the part of the narrator that directly interacts with Storm, his utterances are somewhat more vulgar. For instance, the frequency of the use of swearwords increases noticeably when the experiencing I begins his rant at Storm.

For the reader's inclination to assume the subject positions promoted by the narrator the effect of this increase in swearing depends on the recipient's attitude towards swearing. If he or she approves of it or even finds it enjoyable in this context, he or she will presumably identify further with the narrator's views. If he or she does not approve of swearing, however, then the reader will probably tend towards excluding the narrator's subject positions from his or her identity.

Storm's utterances throughout the text mainly appear to involve rhetorical questions like "Why take drugs / when herbs can solve it" (Minchin 78-79) and absolute statements such as "the human body is a mystery" (59). The experiencing I, during his tirade, uses a similar style as Storm, since he increasingly asks rhetorical questions and makes assertions without necessarily backing them up. For instance, he claims that "there's no such thing as an aura" (130) and does not make any attempt to justify this opinion.

A lack of evidence and explanations for such claims might make the reader wary of both Storm's and the experiencing I's opinion. However, the experiencing I's views are again supported by the narrating I's presence in the text. The narrating I does not intervene or elaborate and therefore, with its seemingly more objective view, seems to agree with the experiencing I, but not Storm. This, too, may well cause the recipient to side with the narrator rather than Storm. 


\section{How Poetry Invites Identification through Pleasure}

\subsection{Pleasure}

In the previous chapter the effects of the narrative system in Storm on the recipient have been examined. Yet the text is a poem and thus has lyric properties as well. The influence of these properties on the reader's inclination to identify will be examined on the basis of the assumption that poetry - as a form of art - can induce pleasure. The recipient's enjoyment of Storm may thus alter his or her tendency to identify with the narrator's views on a more emotional level than the already discussed narrative properties of the text seem to.

First, it must be considered what exactly pleasure does, how it works. Bloom proposes that "uniquely human" pleasures, "such as art, music, fiction, masochism and religion" (xi), are "affected by deeper factors, including what the person thinks about the true essence of what he or she is getting pleasure from" (24). Bloom bases this idea on the notion that human beings "naturally assume that things in the world - including other people - have invisible essences that make them what they are" (xii).

With respect to art he states that "displays of cleverness, discipline, strength, speed, and so on capture our interest because they reveal relevant properties of an individual" (136). This is important because a piece of art (in the case of Storm, a poem) may be considered to be precisely such a display of cleverness, wit, creativity, or some other sort of "valuable positive information about another person" (138). In Storm who that other person is depends on who is considered to speak. In the previous chapter it was assumed that the narrator is the speaking medium and for the sake of simplicity the same will be done here. Thus, it will be presumed that the "valuable positive information" is (mostly) about the narrator ${ }^{22}$, henceforth called the lyric $I^{23}$.

Another claim made by Bloom "is that we have evolved to take pleasure from virtuoso displays. This motivates us to seek out such displays, it drives us to create them ourselves, and it proves a psychological mechanism underlying our attraction to artists - they are capable of creating these objects that give us so much pleasure." (137-138) Thus, if a recipient recognises Storm as such a display, he or she is likely to gain pleasure from it. The fact that "we tend to like those who give us joy" (ibid.), then, means that someone who enjoys Storm will presumably be more in-

22 To some extent, this assumption implies that the poetic properties of the text originate from the narrator and not from the author. As mentioned before, the narrator is of course created by the author and so are the lyric elements of the poem. However, because the narrator and not the author has so far been considered to be the entity that readers may identify with, it will be assumed that the author lets the narrator and characters speak in poetic lines and that the poetry of Storm, thus, is perceived as coming from the narrator and other characters, rather than directly from the author.

23 The term lyric I was simply deemed more appropriate in the context of an examination of lyric qualities. 
clined to share the lyric I's views and therefore to incorporate the subject positions represented by the lyric I into his or her identity. This may seem commonsensical, but it is relevant nonetheless. However, why exactly should recipients appreciate Storm as an artistic display?

Bloom argues that "the perceived amount of effort" (141) that has gone into a piece of art plays a crucial role for people's assessment of it. The fact that "More effort leads to greater pleasure" (ibid.) means that in order to be appreciated by recipients, Storm must be recognised as an artistic display. An aspect of the text that might elicit this recognition is its sheer length: it is two hundred and forty-seven lines long (in the transcription used here), which for a poem is considerable, one might argue. In combination with the fact that the poem is also mostly written in rhyme, some of which may seem rather inventive - for instance the use of the end assonance ${ }^{24}$ of "favour" and "Australia" (Minchin 13-14) - the length may certainly show that a certain creative effort has been made ${ }^{25}$. Naturally, a reader may also find Storm distasteful and crude, in which case the disapproval will presumably have the opposite effect of pleasure (i.e. decrease his or her inclination to identify with presented views and beliefs).

If Storm is recognised as an artistic display, however, the recipient may gain pleasure from the text and become more inclined to accept the lyric I - even the entirety of the text - as a promoter position. Thus, the pleasure derived from Storm may serve to raise the recipient's openness for interpellation by certain elements of the content, thus indirectly affecting the reader's inclination to identify with subject positions represented in it. Furthermore, it could be argued that pleasure can also directly influence interpellation. If the joy derived from the text occurs in response to the humorous ridicule of a character, then that is an instance of exclusion. "Being laughed at is a surefire way of feeling put in your place - your place being absolutely not the place of those doing the laughing" (Medhurst 20) and thus, exclusion through ridicule, can be a strong instance of interpellation, uniting those who gain pleasure from it against those who are ridiculed.

This also happens in Storm. After a rather lengthy and conceptual explanation why so-called alternative medicine is not universally recognised as adequate, the narrator rhetorically asks Storm, "Do you know what they call alternative medicine that's been proved to work? / 'Medicine'." (Minchin 92-94). The humour - the pleasure - may here arise because suspense is built up when expectations of a complex, intellectualised answer to the question are raised. That suspense is released when the answer - in stark contrast to those expectations - turns out to be

24 Nünning and Nünning define "end assonance/vowel rhyme" as "congruence between vowel sounds only" (62).

25 Of course, rhyme is not the only poetic quality of Storm. However, the transcription used here is not meant to be a precise representation of elements like rhythm and metre. Therefore, an examination of these elements would seem speculative in this context. Rhyme and sound patterns largely remain recognisable even when the visual structure of the poem is altered and can therefore be considered here without too great a risk of inadequacy. 
blatantly simple. This play with the reader's expectations may be seen as humorous and therefore pleasurable.

The capacity of this passage to ridicule and exclude arises from a combination of the implication that Storm is naive and misinformed, and the pleasure derived from the witty way in which the narrator points this out (if it is perceived as witty). The recipient will most likely not be inclined to side with the ridiculed Storm and will therefore presumably lean towards occupying the narrator's subject positions.

\subsection{The Pleasure of Poetry}

The general recognition of Storm as art probably depends not only on the overall effort that seems to have gone into its creation. "What matters more", Bloom states, "is our intuitions about creativity and genius." (142) This means that perceived effort needs to go along with perceived originality or skill of some sort. "You need to be dazzled by the idea to be dazzled by the art" (146), and "our clashing intuitions about the quality of such artwork derive in large part from what we think of the performance. If you have a low opinion of the capabilities underlying a creation, then you will see it as bad art and get no pleasure from it" (ibid.), as Bloom puts it. Thus, it may prove useful to try to pinpoint instances in Storm where relatively creative or clever lyric devices are employed, because these may influence the reader's perception of specific views expressed in the poem.

The focus in the following analysis will be on imagery and comparisons because they can serve "to evoke the subject in a certain way or for a particular response" (Nelson 3) ${ }^{26}$, but can also give pleasure if they seem particularly inventive or appropriate. Thus, the recipient's tendency to identify with subject positions represented in Storm may in such cases be influenced both by the manner in which views are articulated, and by the emotional association of the voicing of those views with pleasure. However, this is not to say that elements other than comparisons are only capable of eliciting either pleasure or insight.

Rhyme, for instance, "is not simply an end in itself, but a way to emphasise certain words, and thus their meaning and connotations" (10). Yet, "rhyme and other special sound effects" may also "certainly add to the pleasure we receive" (ibid.) from poetry. The reason why imagery rather than phonological or structural aspects of Storm will be focused on in the analysis is that the connection between them and the argumentation in the text seems more obvious, because they "characterise the subject in ways that enhance our appreciation and understanding of it" (3). Rhyme, on the other hand, may certainly be used to emphasise words, but does not add extra meaning to them. Therefore an examination of the possible consequences of such emphasis would seem highly speculative and inadequate here.

26 The "subject" Nelson speaks of is the topic of a given piece of poetry, not the subject discussed in chapter 2 . 
Regarding rhythm and metre, the same problem occurs: "Any change in the metrical pattern usually means that the poet wishes to emphasise the word receiving the stress" (12). However, adding to the fact that stress alone does not enhance a word's meaning, the rhythm in the transcription used here cannot be considered to be entirely accurate (see chapter 1.), so an inquiry into its importance does not seem adequate here. Metaphors and similes on the other hand carry meaning of their own and are therefore easier to examine in context with the arguments put forward in the poem.

\subsection{Pleasurable Imagery in Storm}

In order not to render the analysis of imagery too lengthy, two particular examples will be examined here. The following occurs fairly early in the poem and has already been mentioned when the narrator's attitude was examined:

And when she says: "I'm sagittarian",

I confess a pigeon hole starts to form

and is immediately filled with pigeon

when she says her name is 'Storm'. (Minchin 28-31)

Firstly, why is this a metaphor? "Metaphor involves the removal of a word from its original semantic field and projection of this word onto an element from another semantic field." (Nünning and Nünning) In this case, the noun whose meaning changes is "pigeon hole", because what is meant here is not "a small recess for a domestic pigeon to nest in" or "each of a set of small open-fronted compartments in a workplace" (Oxford Dictionary of English 2005), but a prejudice about Storm in the lyric I's mind. In saying that he "confesses" that this prejudice is evoked by Storm's apparent belief in the importance of star signs, the lyric I seems to show that he feels slightly guilty for categorising her according to such a stereotype. However, the pigeon hole "is immediately filled with pigeon / when she says her name is 'Storm", which to him means that his labelling was, in fact, justified. Thus, due to the lyric I's seemingly acceptable labelling of Storm according to his prejudices about "hippies" (241), the reader might get the idea that his or her own pigeonholing of Storm is justified as well. Naturally, this can only happen if the recipient really has similar prejudices or has at least heard of the stereotypes which Storm seemingly perpetuates. The metaphor here may thus to some extent serve to illustrate the validation of the lyric I's preconceptions about Storm.

Yet the imagery may also work as a source of pleasure to the reader. As explained before, creativity and cleverness have the capability to give joy to the recipient. The use of the term "pigeon hole" in the sense in which it is employed here may well be seen as quite inventive, and the idea of it being filled with conceptual "pigeon" rather than 'pigeons' may certainly appear unusual and clever. If pleasure is evoked in the recipient in this way, his or her possible feeling of guilt 
for adhering to prejudices about "hippies" and for his or her lack of openmindedness may subside. Perhaps the pleasure might even be associated with the stereotyping of Storm, which might then be perceived as something desirable, even for readers who did not hold the stereotypes before reading the text.

The prejudices that are evoked or reinforced in this way presumably decrease the recipient's inclination to identify with Storm, since she is demonstratively categorised by the lyric I as 'other'. Furthermore, if the reader here receives pleasure from the text, he or she is likely to become more open towards incorporating subject positions represented in it into his or her identity. Since the happenings in the text are relayed through the perspective of the lyric I, most of those subject positions in it are probably the ones held and promoted by the lyric I.

It can thus be seen that metaphors both on the level of emotional pleasure and due to their capability to illustrate and explain thoughts and feelings can help to align the reader's identity with the views held by the lyric I.

The second example of imagery examined here can be seen in the following two passages. "And, try as I like, / a small crack appears / in my diplomacy-dyke" (85-87), and:
Maybe it's the Hamlet she just misquothed or the fifth glass of wine I just quaffed, but my diplomacy-dyke groans and the arsehole held back by its stones can be beld back no more. (124-128, emphasis added)

When the lyric I first says "a small crack appears / in my diplomacy-dyke", the image that springs to mind is probably that Storm, like an actual storm, is responsible for his decreasing self-control because he is annoyed at her apparent inconsideration and her allegedly false opinions. Earlier she is described as being "like her meteorological namesake", (71) and thus the comparison between her and a great storm that causes a breach in an embankment illustrates that she is allegedly responsible for the lyric I's increasing loss of self-restraint. The lyric I is displayed as a victim of his incapability to cope with the offence that Storm seemingly causes. When the "diplomacy-dyke groans / and the arsehole held back by its stones / can be held back no more", the imagery gains a third element: the "arsehole", the part of his personality which the lyric I tried to suppress.

In the metaphor, this element has not explicitly been mentioned until this point. Thus, it may serve to let the lyric I appear in a favourable light, as it suggests that he was not trying to contain himself, but that uncivilised part of himself, which somehow comes across as a separate entity here. The lyric I is to some degree portrayed as the innocent maintainer of the "diplomacy-dyke" who is helpless in the face of the natural disaster that Storm comes to represent. The implication is that he cannot be held responsible for his ensuing rudeness, and that Storm only has herself to blame for being ranted at by him. The recipient will therefore proba- 
bly deem the lyric I's following tirade to be far less inappropriate, as this reaction is to some extent justified by blaming it on Storm rather than on the narrator.

Furthermore, the maritime and meteorological imagery may - like the pigeon hole earlier - be perceived as rather creative, since it could be argued that it has a certain intricacy to it. For example, one would usually expect a dyke to protect settlements in coastal areas from floods caused by storms. In the metaphor in Storm, however, the reader soon comes to realise that the dyke is not meant to keep Storm from causing harm, but to protect her from the raging storm of the lyric I's furious rant. If the reader finds this use of imagery clever and sophisticated, then he or she will most likely derive pleasure from it, pleasure that is associated with the voice of the lyric I and thus causes a higher affinity of the recipient's subject to the lyric I's subject positions.

\section{Conclusion}

It has been made clear in this analysis that Storm seems to be laid out to convince the recipient to identify with the subject positions represented by the narrator. Both the narrative system and the use of poetic devices to evoke pleasure serve to achieve this in various ways: they elicit and support the establishment of the narrator (or lyric I) as a promoter position, they increase the reader's openness to and the potency of interpellation by elements of the text and they serve to demote Storm and her views. All of these effects certainly lead to an increased inclination of the recipient's subject to assume the subject positions promoted by the narrator by showing them in a favourable light. Especially the subjectivity created through narrative devices, but also through the ridicule of Storm serve to exclude her subject positions from being considered for identification and to render her as part of the reader's other.

Conducting a more detailed survey of the narrative situation and the lyric in Storm would likely reveal a different but equally reasonable reading of the text, since, as observed a few times, neither the effects of the narrative structure nor those of the poetic qualities of the text are unambiguous. The narrator's standpoint may well be subverted by either in many instances. Yet it ultimately seems to depend on the individual perceiving the poem whether approval and identification or disapproval and 'othering' of the narrator's subject positions occurs. Particularly the poetry of the text may well be perceived as quite unoriginal and lacking in virtuosity. For instance, the syntactic structure barely seems to differ from ordinary prose which may be seen as evidence of a lack of skill by the author. Furthermore, if the subjectivity of the narrator and his demeanour are consciously perceived and evaluated by readers, they may deem the narrator untrustworthy, presumably making them wary and unwilling to identify with the subject positions promoted by him. It could also be argued simply with regard to the argumentation of the narra- 
tor that he more than once subverts his own standpoint by contradicting his own principles ${ }^{27}$.

The aim of this paper, however, was simply to examine whether the narrative and poetic devices in Storm elicit identification with the narrator. That, it seems, is indeed the case.

27 For instance, he seems to insist that Storm's behaviour is inconsiderate, yet behaves quite similarly, perhaps even worse towards the end of the poem. 


\section{Transcript: Tim Minchin's Storm the Animated Movie}

Inner north London, top floor flat, all white walls, white carpet, white cat, rice paper partitions,

5 modern art and ambition, the host's a physician, bright bloke, has his own practice, his girlfriend's an actress, an old mate of ours from home and they're always great fun, so to dinner we've come.

The fifth guest is an unknown.

The hosts have just thrown us together for a favour, 'cause this girl's just arrived from Australia and she's moved to North London and she's the sister of someone or has some connection.

As we make introductions I'm struck by her beauty, she's irrefutably fair with dark eyes and dark hair, but as she sits, I admit, I'm a little bit wary, 'cause I notice the tip of the wing of a fairy tattooed on that popular area just above the derrière. And when she says: "I'm sagittarian", I confess a pigeon hole starts to form and is immediately filled with pigeon when she says her name is 'Storm'.

Conversation is initially bright and light-hearted, but it's not long before Storm gets started:

"You can't know anything, knowledge is merely opinion!", she opines over her Cabernet Sauvignon vis-à-vis some un-hippily 
empirical comment made by me.

Not a good start, I think, we're only on pre-dinner drinks and across the room my wife widens her eyes, silently begs me: "Be nice!"

A matrimonial warning not worth ignoring, so I resist the urge to ask Storm whether knowledge is so loose weave of a morning

when deciding whether to leave her apartment by the front door or the window on her second floor.

The food is delicious and Storm,

Whilst avoiding all meat

Happily sits and eats as the good doctor, slightly pissedly, holds court

on some anachronistic aspect of medical history when Storm suddenly insists:

"But the human body is a mystery!

Science just falls in a hole when it tries to explain the the nature of the soul!"

My hostess throws me a glance.

She, like my wife, knows there's a chance

I'll be off on one of my rare, but fun, rants, but I shan't, my lips are sealed,

I just want to enjoy the meal And although Storm is starting to get my goat, I have no intention of rocking the boat.

Although it's becoming a bit of a wrestle, because like her meteorological namesake Storm has no such concerns for our vessel. "Pharmaceutical companies are the enemy! They promote drug dependency at the cost of the natural remedies 
that are all our bodies need! They are immoral and driven by greed!

Why take drugs

80 when herbs can solve it?

Why use chemicals when homoeopathic solvents can resolve it?

I think it's time we all returned to live with natural medical alternatives."

85

And, try as I like, a small crack appears

in my diplomacy-dyke.

"By definition", I begin,

90

"alternative medicine", I continue, "has either not been proved to work, or been proved not to work.

Do you know what they call alternative medicine that's been proved to work?

'Medicine'."

"So you don't believe in any natural remedies?"

"On the contrary, Storm. Actually, before I came to tea

I took a remedy

100

derived from the bark of a willow tree, a painkiller that's virtually side-effect free.

It's got a weird name

darling, what was it again?

maspirin?

105

Er, baspirin?

Oh yes, aspirin!

which I paid about a buck for

down at the local drug store."

The debate briefly abates

110

as my hosts collect plates,

but when they return with dessert

Storm pertly asserts:

"Shakespeare said it first:

'There are more things in heaven and earth 
than exist in your philosophy.'

Science is just how we're trained to look at reality.

It doesn't explain love or spirituality.

How does science explain psychics, auras, the afterlife, the power of prayer?"

120

I'm becoming aware that I'm staring.

I'm like a rabbit suddenly trapped in the blinding headlights of vacuous crap. Maybe it's the Hamlet she just misquothed or the fifth glass of wine I just quaffed, but my diplomacy-dyke groans and the arsehole held back by its stones can be held back no more.

"Look, Storm, sorry, I don't mean to bore you, but there's no such thing as an aura.

Reading auras is like reading minds, or tea leaves, or star signs or meridian lines.

These people aren't plying a skill, they're either lying or mentally ill!

135 Same goes for people who claim they can hear God's demands, or spiritual healers who think they've got magic hands.

By the way, why do we think it's OK for people to pretend they can talk to the dead?

140 Isn't that totally fucked in the head? Lying to some crying woman, whose child has died and telling her you're in touch with the other side? I think that's fundamentally sick

Do we need to clarify here that there's no such thing as a psychic?

What, are we fucking two?

Do we actually think that Horton heard a Who?

Do we still believe that Santa brings us gifts?

That Michael Jackson didn't have facelifts?

Are we still so stunned by circus tricks

that we think the dead would want to talk to pricks like John Edward?"

Storm, to her credit, despite my derision, 
155

160 keeps firing off clichés with startling precision

like a sniper using bollocks for ammunition:

"You're so sure of your position, but you're just closed-minded.

I think you'll find that your faith in science and tests is just as blind as the faith of any fundamentalist."

"Wow, that's a good point. Let me think for a bit ...

Oh wait, my mistake, that's absolute bullshit.

Science adjusts its views based on what's observed. Faith is the denial of observation so that belief can be preserved.

If you show me that, say, homoeopathy works, then I will change my mind, I will spin on a fucking dime, I'll be as embarrassed as hell, yet I will run through the streets yelling: 'It's a miracle! Take physics and bin it! Water has memory,

and whilst it's memory of a long lost drop of onion juice seems infinite, it somehow forgets all the poo it's had in it!'

You show me that it works and how it works, and when I've recovered from the shock

I will take a compass and carve 'Fancy That' on the side of my cock."

Everyone is just staring now, but I'm pretty pissed and I've dug this far down so I figure: in for a penny in for a pound.

"Life is full of mysteries, yeah.

But there are answers out there and they won't be found by people sitting around looking serious and saying 'Isn't life mysterious?

Let's sit here and hope! Let's call up the fucking pope!

Let's go watch Oprah interview Deepak Chopra!'

If you want to watch telly, you should watch Scooby Doo.

That show was so cool, because every time there was a church with a ghoul 
or a ghost in a school

they looked beneath the mask and what was inside?

The fucking janitor or the dude who ran the water-slide.

Because throughout history

every mystery

ever solved has turned out to be

200 not magic.

Does the idea that there might be knowledge

frighten you?

Does the idea that one afternoon

on Wiki-fucking-pedia might enlighten you

205 frighten you?

Does the notion that there may not be a supernatural

so blow your hippy noodle

that you'd rather just stand in the fog

of your inability to google?

Isn't this enough?

Just this world?

Just this beautiful, complex, wonderfully unfathomable natural world?

How does it so fail to hold our attention

215

that we have to diminish it with the invention

of cheap, man-made myths and monsters?

If you're so into your Shakespeare,

lend me your ear:

To gild refined gold, to paint the lily,

to throw perfume on the violet ... is just fucking silly ...

or something like that.

Or what about Satchmo?!

'I see trees of green, red roses too ...'

And fine, if you wish to

glorify Krishna and Vishnu

in a post-colonial, condescending,

bottled-up and labelled kind of way then whatever, that's OK,

but here's what gives me a hard-on:

I am a tiny, insignificant, ignorant bit of carbon.

I have one life, and it is short and unimportant ...

But thanks to recent scientific advances 
235

I get to live twice as long

as my great great great great uncleses and auntses.

Twice as long to live this life of mine.

Twice as long to love this wife of mine.

240

Twice as many years of friends and wine, of sharing curries and getting shitty at good-looking hippies With fairies on their spines and butterflies on their titties.

And if perchance I have offended think but this and all is mended: we'd as well be ten minutes back in time for all the chance you'll change your mind." 


\section{Works Cited}

Althusser, Louis. Lenin and Philosophy, and Other Essays. 1971. New York: Monthly Review Press, 2001. Print.

Baumeister, Roy F. and Mark R. Leary. "The Need to Belong: Desire for Interpersonal Attachments as a Fundamental Human Motivation." Psychological Bulletin 117.3 (1995): 497-529. Print.

Bhabha, Homi K. The Location of Culture. London: Routledge, 1994. Print.

Bloom, Paul. How Pleasure Works: The New Science of Why We Like What We Like. New York: W. W. Norton, 2010. Print.

Brah, Avtar. "Difference, Diversity and Differentiation." "Race", Culture, and Difference. Ed. James Donald and Ali Rattansi. London: Sage Publications in association with the Open University, 1992. 126-146. Print.

Butler, Judith. Gender Trouble: Feminism and the Subversion of Identity. New York: Routledge, 1990. Print.

Butler, Judith. Bodies That Matter: On the Discursive Limits of "Sex". New York: Routledge, 1993. Print.

Ferretter, Luke. Louis Althusser. London: Routledge, 2006. Print.

Freud, Sigmund. Freud: The Major Works of Sigmund Freud. Ed. Wallace Brockway. Chicago: Encyclopaedia Britannica, 1952. Great Books of the Western World 54. Print.

Hall, Stuart. "Introduction: Who Needs 'Identity?”" Questions of Cultural Identity. Ed. Stuart Hall and Paul Du Gay. London: Sage, 1996. 1-17. Print.

Hermans, Hubert J. M., and Thorsten Gieser. "Introductory Chapter: History, Main Tenets and Core Concepts of Dialogical Self Theory." Handbook of Dialogical Self Theory. Ed. Hubert J. M. Hermans and Thorsten Gieser. Cambridge: Cambridge University Press, 2012. 1-22. Print.

Luhmann, Niklas. Social Systems. Stanford, California: Stanford University Press, 1995. Print.

Medhurst, Andy. A National Joke: Popular Comedy and English Cultural Identities. London: Routledge, 2007. Print.

Minchin, Tim, Dan C. Turner and Tracy King. "Tim Minchin's Storm the Animated Movie." Youtube. Stormmovie.net. 7 April 2011. 17 June 2012. <http://www.youtube.com/watch?v=HhGuXCuDb1U>

Nelson, Nicolas H. The Pleasure of Poetry: Reading and Enjoying English Poetry from Donne to Burns. Westport, Connecticut: Praeger, 2006. Print. 
Nobus, Dany. "Lacan's Science of the Subject: Between Linguistics and Topology." The Cambridge Companion to Lacan. Ed. Jean-Michel Rabaté. Cambridge: Cambridge University Press, 2003. 50-68. Print.

Nünning, Vera, and Ansgar Nünning. An Introduction to the Study of English and American Literature. 1st ed. Stuttgart: Klett Sprachen, 2004. Print.

Petersen, Jürgen H. Erzählsysteme: Eine Poetik epischer Texte. Stuttgart: J.B. Metzler, 1993. Print.

Rutherford, Jonathan. "A Place Called Home: Identity and the Cultural Politics of Difference." Identity: Community, Culture, Difference. Ed. Jonathan Rutherford. London: Lawrence \& Wishart, 1990. 9-27. Print. 